\title{
m contato entre línguas na constituição da realidade sócio-histórica do português brasileiro: aspectos para um estudo sociolinguístico
}

\section{The contact between languages in the constitution of socio-historical reality of Brazilian Portuguese: aspects for a sociolinguistic study}

\author{
Marcelo da Silva Souza * \\ Universidade Estadual de Feira de Santana \\ Feira de Santana, Bahia, Brasil \\ Josane Moreira de Oliveira** \\ Universidade Estadual de Feira de Santana \\ Feira de Santana, Bahia, Brasil \\ Silvana Silva de Farias Araújo *** \\ Universidade Estadual de Feira de Santana \\ Feira de Santana, Bahia, Brasil
}

\begin{abstract}
Resumo: Este artigo busca refletir sobre o processo de formação sócio-histórica do português brasileiro (PB), colocando como peça central a situação de contato linguístico por que passaram as línguas europeia, indígenas e africanas no decurso temporal de quatro séculos. A partir daí, são revisitados conceitos que dão conta de remontar o contexto histórico em cujo âmago os elementos do PB foram se desenvolvendo. Discutem-se, assim, conceitos emergentes como o processo de Transmissão Linguística Irregular (TLI), colocando-a como principal norteadora do estudo e enfatizando-se o seu lugar na constituição das variedades do PB e na desconstrução da ideia de que poderia ter surgido no Brasil uma língua crioula típica. Por fim, apresentamos o processo histórico da polarização sociolinguística do Português Brasileiro, situando-o em períodos diferentes.
\end{abstract}

Palavras-chave: Formação do PB. Sócio-história do PB. Contato linguístico.

Abstract: This article seeks to reflect on the process of socio-historical formation of Brazilian Portuguese (BP), placing as a central piece the situation of linguistic contact through which the European, indigenous and African languages have passed in the course of four centuries. From then on, we revisit concepts that give an account of reassembling the historical context in whose core the elements of PB were developing. Thus, we discuss emerging concepts such as the Irregular Linguistic Transmission (TLI) process, placing it as the main guide of the study and emphasizing its place in the constitution of the PB varieties and in the deconstruction of the idea of this process could have arisen in Brazil a typical Creole language. Finally, we take the historical process to the sociolinguistic polarization of Brazilian Portuguese, placing it in different periods.

Keywords: Constitution of BP. Socio-history of BP. Linguistic contact.

* Estudante de Mestrado do Programa de Pós-Graduação em Estudos Linguísticos da Universidade Estadual de Feira de Santana. E-mail: marcelo.souza@ufob.edu.br.

** Professora Doutora da Universidade Estadual de Feira de Santana (Orientadora). E-mail: josanemoreira@hotmail.com.

*** Professora Doutora da Universidade Estadual de Feira de Santana. E-mail: silvana.uefs.2014@gmail.com. 


\section{PINÇANDO UMA INTRODUÇÃO}

Muitos estudos foram realizados acerca da constituição sócio-histórica do português brasileiro (PB) e não é nova a ideia de que há um consenso de que a realidade linguística do português brasileiro é extremamente diversificada e, por isso mesmo, rica nas diversas possibilidades de variação em que se acham desveladas situações ligadas a fatores que extrapolam a superfície gramatical e chegam a fatores de cunho social.

A língua é, por assim dizer, heterogênea e, como tal, mutável. Dizemos que o português, assim como todas as línguas, muda no decurso do tempo. Se compararmos o português atual (no sentido lato sensu), por exemplo, com o latim, claras serão as evidências de que a língua é um instrumento social e, por isso mesmo, mutável. Se bem que não é preciso ir muito longe nesse sentido para perceber essas transformações, pois a própria trajetória histórica do português medieval, conforme assevera Naro (2015, p. 43), dá conta de mostrar "diferenças em todos os níveis, desde a semântica até a sintaxe, passando pela fonologia, pelo léxico, pela morfologia etc.".

A despeito da questão da heterogeneidade do português brasileiro, que autores como Mattos e Silva (2004), Baxter, Lucchesi e Ribeiro (2009) e Lucchesi (2009, 2015) se dedicaram a estudar, fica evidente, por meio dos resultados de suas pesquisas, que o português não é apenas um, mas um conjunto de variedades que se legitimam como completo para compor um processo de comunicação, em cujo âmago os interlocutores compreendem e se fazem compreendidos.

Detemos nossa abordagem na formação do português brasileiro, pinçando brevemente o processo histórico, dando enfoque aos três primeiros séculos da Colonização, de modo a considerar as situaç̧ões de contato por que passou o português europeu (PE) com as línguas indígenas e as diversas línguas africanas dos negros escravizados ${ }^{1}$ trazidos para o Brasil quando de sua exploração para produção de riquezas e trabalho pesado.

Assim, neste artigo, desenvolvemos uma reflexão, fazendo uma abordagem, em primeiro momento, sobre o contato entre línguas mencionado anteriormente. Em um segundo momento, é apresentado o conceito elementar emergente do referido contato linguístico, a saber: o processo de transmissão linguística irregular (TLI). E, em um terceiro plano, desenvolvemos uma explanação da apreensão de conceito de polarização sociolinguística que se desenha no português brasileiro. Por fim, tecemos algumas considerações finais acerca do que foi proposto neste artigo.

\section{A CHEGADA DO PORTUGUÊS EUROPEU AO BRASIL E O CONTATO LINGUÍSTICO COM OS INDÍGENAS}

\footnotetext{
1 Optou-se por denominar os negros trazidos da África para o Brasil como "escravizados" em vez de "escravos". Considera-se, neste artigo, o termo mais adequado às situações histórico-sociais a que foram submetidos os referidos negros. Entretanto, nas citações de outros estudos trazidas para o corpo do texto, preservam-se tais como aparecem na obra-fonte, o que faz aparecer a palavra "escravos" como sinônimo de "escravizados".
} 
De fato, os primeiros portugueses, trazidos pela esquadra de Pedro Álvares Cabral com o plano de explorar as riquezas do território brasileiro a mando da Coroa portuguesa, fazem com que a língua portuguesa europeia atravesse o Oceano Atlântico, por volta de 1500 .

Chegando em terras brasileiras, o português europeu entrou inicialmente em situação de contato linguístico com línguas indígenas de diversas etnias, por meio da convivência intensa estabelecida com os nativos. Nesse período, eram faladas cerca de 1300 línguas indígenas, conforme Rodrigues (1993), que, mais tarde, foram se dizimando por conta de um cenário marcado por imposições dos portugueses e lutas destes com índios, chegando não raramente ao que se entende por genocídio.

De toda sorte, um fator que contribuiu para que esse contato entre as línguas indígenas e o português europeu se intensificasse foi a ausência de mulheres brancas, o que "levou os portugueses a se acasalarem com as nativas. Portanto o tipo de família brasileira [...] era mestiça" (TEIXEIRA, 2013, p. 148).

Com a chegada dos colonos lusitanos e com a formação das primeiras cidades, por volta de 1530, aportaram no Brasil os Jesuítas, que tinham como objetivo maior difundir o Cristianismo e catequizar os nativos indígenas, tendo papel essencial para que o contato entre a língua lusófona e as línguas indígenas fosse potencializado. Para Fernandes (2017),

como notórios intelectuais que eram, os jesuítas logo conseguiram assimilar e compreender os dialetos nativos falados pelos índios. Com o tempo, o conhecimento desses dialetos, associado à estrutura da língua portuguesa, possibilitou aos jesuítas a criação de um novo idioma, que passou a ser largamente usado em quase todo o território colonial brasileiro. Esse idioma ficou conhecido como "Língua Geral", ou "língua brasílica". O ponto de partida da Língua Geral foi o tupi, dialeto falado pelos tupinambás, povos indígenas que habitavam o litoral do Brasil. O desenvolvimento dessa língua possibilitou um maior entendimento da organização social dos índios e, por conseguinte, facilitou a ação de conversão operada pelos jesuítas. (FERNANDES, 2017, grifos do autor) ${ }^{3}$

É nesse cenário que se percebe uma certa "fusão linguística", por assim dizer. A Língua Geral tornou-se, nos séculos XVI e XVII, o principal veículo de comunicação no Brasil Colônia, fazendo com que seu uso fosse superior ao uso do português nesse contexto, situação que perdurou até a proibição do uso de línguas indígenas no território brasileiro decorrente de um pacote de medidas adotadas pelo Marquês de Pombal, ministro da Coroa portuguesa, no século XVIII, quando de fato, até certo ponto, se freou o que Mattos e Silva (2004) chama de "multilinguismo generalizado". Nesse sentido, Fernandes (2017) acentua que

um dos pontos das reformas de Pombal era a expulsão dos jesuítas das colônias portuguesas a fim de ter maior controle institucional, já que os jesuítas tinham um grande peso na

2 Embora tenha sido conservado o termo "acasalarem" conforme a obra-fonte, tem sido evitada a sua utilização para referir-se ao ato sexual entre seres humanos, por ser considerado, nesse contexto, um termo pejorativo.

${ }^{3}$ Disponível em:<http://brasilescola.uol.com.br/historiab/lingua-geral-no-contexto-brasil-colonial.htm $>$. 
organização social do Brasil Colônia. Com a perseguição e expulsão dos jesuítas, a transmissibilidade da Língua Geral ficou comprometida e sua extinção foi inevitável. (FERNANDES, 2017) ${ }^{4}$

Por essas evidências, constata-se um cenário favorável à afirmação de que o povo indígena legou, a partir do contato histórico com a língua portuguesa, inúmeras contribuições à formação do $\mathrm{PB}$, contribuições estas percebidas, inclusive, no português brasileiro atual.

\section{A CHEGADA DOS NEGROS ESCRAVIZADOS AO BRASIL E O CONTATO DAS LÍNGUAS AFRICANAS COM O PORTUGUÊS}

O outro elemento do tripé linguístico que configura a formação sócio-histórica do português brasileiro são as línguas africanas. As primeiras levas de imigrantes escravizados chegaram por volta de 1549 e a situação de escravidão propriamente dita perdurou até final do século XIX, com a Lei Áurea. Para Teixeira (2013),

com a chegada dos escravos africanos, que se tornaram o contingente mais numeroso a partir do século XVII, o cenário linguístico do Brasil, em especial da Bahia, muda a sua configuração: além do português, da língua geral, das diversas línguas indígenas, a colônia foi marcada pela presença de línguas africanas. (TEIXEIRA, 2013, p. 148)

Um destaque maior se deve a esse elemento do tripé, uma vez que, diferentemente do que aconteceu com os índios em situação inicial de contato, a relação com os negros foi estabelecida a partir de forma violenta, sem nenhum tipo de negociação nem maquiagem dessas formas desde a abrupta retirada destes de suas terras natais africanas.

Enquanto os jesuítas tiveram que encontrar formas de assimilar as línguas indígenas, para, a posteriori, estabelecer uma comunicação mais geral na Colônia, os escravos tiveram que aprender, num sistema babélico, a língua portuguesa, veículo de comunicação dos senhores de engenho e pessoas do topo da pirâmide social de então.

Mas, de fato, a grande relevância dedicada às línguas africanas no contexto de formação do PB é justamente o fato de os índios, em face do estilo de vida empedernida no tocante a serem "controlados", terem se afastado dos povoamentos, tornando o contato menos intensificado se comparado ao dos africanos escravizados.

Os negros, pelo contrário, além de terem vivido em geral em situações nas quais o uso do português era o fio de comunicação nas relações hierárquicas entre capatazes e escravizados, ainda, e por isso mesmo, eram dotados de experiência com lavouras, engenhos de cana-de-açúcar e outras produções braçais. Isso não significa que os índios também não tenham sido escravizados e não tenham contribuído com o serviço braçal. Aliás, muito contribuíram com a extração e carregamentos de madeiras, mas muitos deles não aguentavam os castigos que lhes eram aplicados e morriam.

É salutar frisar que esses negros vieram de regiões as mais diversas possíveis do continente africano - como, por exemplo, da Senegâmbia, Angola, Reino do Congo, entre

${ }^{4}$ Disponível em:<http://brasilescola.uol.com.br/historiab/lingua-geral-no-contexto-brasil-colonial.htm>. 
outros -, o que os colocava numa situação muito difícil para se comunicarem até mesmo entre si, já que as línguas maternas eram diferentes e diversas. Estava, assim, posto que aprendessem a falar o português. Mas como? Sem instrução formal oriunda dos centros sistematizados de ensino, recolhidos apenas aos integrantes da elite da Colônia, ou seja, pela assimilação em condições emergenciais e defectivas da língua de superestrato ${ }^{5}$.

Segundo Baxter, Lucchesi e Ribeiro (2009), o contato por que passou o português com as línguas africanas, tendo em vista a recorrente chegada de negros ao Brasil durante três séculos, não gerou uma língua crioula, mas uma variedade do português. A esse processo, que deixou marcas na morfossintaxe do português brasileiro, os autores chamam de "transmissão linguística irregular", sobre a qual faremos algumas apresentações na seção 3 .

Pelo que foi apresentado anteriormente, fica clara a fotografia sociolinguística do Brasil na dimensão de contato entre línguas, em que os portugueses junto a seus descendentes diretos constituíram, no período estendido do Brasil colonial e imperial, apenas um terço da população, quando fica claro que os outros dois terços são compostos por africanos, com maior predominância, junto a índios e seus descendentes.

\begin{tabular}{c|c|c|c|c|c}
\hline ETNIA & $\mathbf{1 5 8 3 - 1 6 0 0}$ & $\mathbf{1 6 0 1 - 1 7 0 0}$ & $\mathbf{1 7 0 1 - 1 8 0 0}$ & $\mathbf{1 8 0 1 - 1 8 5 0}$ & $\mathbf{1 8 5 1 - 1 8 9 0}$ \\
\hline Africanos & $20 \%$ & $30 \%$ & $20 \%$ & $12 \%$ & $2 \%$ \\
\hline Negros brasileiros & - & $20 \%$ & $21 \%$ & $19 \%$ & $13 \%$ \\
\hline Mulatos & - & $10 \%$ & $19 \%$ & $34 \%$ & $42 \%$ \\
\hline Brancos brasileiros & - & $5 \%$ & $10 \%$ & $17 \%$ & $24 \%$ \\
\hline Europeus & $30 \%$ & $25 \%$ & $22 \%$ & $14 \%$ & $17 \%$ \\
\hline Índios integrados & $50 \%$ & $10 \%$ & $8 \%$ & $4 \%$ & $2 \%$ \\
\hline
\end{tabular}

Tabela 1: População do Brasil por etnia do século XVI ao XIX Fonte: Mussa (1991, p. 163)

Essa situação fica mais clara quando esquematizada na tabela abaixo, tomada de Mussa (1991, p. 163), que sintetiza a população do Brasil no decurso temporal de quatro séculos. Pode-se ilustrar a relação de predominância do número de negros no cenário sociolinguístico de formação do português brasileiro, o que, portanto, solidifica a impossibilidade de negação das fortes influências e interferências negras nas variedades linguísticas observadas no PB.

\section{O CONCEITO DE TRANSMISSÃO LINGUÍSTICA IRREGULAR}

${ }^{5}$ Para Dubois et alii (2014, p. 538), “superestrato designa toda língua que é introduzida largamente na área de outra língua, mas sem substituí-la, podendo desaparecer finalmente e deixando alguns traços”. 
Entende-se por Transmissão Linguística Irregular (TLI), nos termos de Baxter, Lucchesi e Ribeiro (2009), o processo que acontece quando a denominada língua de superestrato ou língua alvo

se impõe de modo que os falantes das outras línguas, em sua maioria adultos, são forçados a adquiri-la em condições bastante adversas de aprendizado, em função de sua sujeição e marginalização. As variedades de segunda língua que se formam nessas condições, mais ou menos defectivas consoante as especificidades de cada contexto histórico, acabam por fornecer os modelos para a aquisição da língua materna para as novas gerações de falantes, na medida em que grupos dominados vão abandonando as suas línguas nativas. (BAXTER; LUCCHESI; RIBEIRO, 2009, p. 101)

Assim, as crianças nascidas nesse contexto não acessavam a língua materna de seus genitores - estes muitas vezes falantes de línguas que não se faziam entendidas -, tendo que desenvolver a sua língua materna baseada em um modelo muito deficitário de português falado como segunda língua por seus pais.

A TLI dá condições para que outros conceitos emergentes se formem. A formulação do conceito de TLI objetiva, há quase vinte anos, segundo Lucchesi (2015, p. 95), "estender o escopo das mudanças que afetam a estrutura gramatical da língua em situação de contato massivo, para além da pidginização e da crioulização típicas". Assim, Lucchesi (2015) oferece-nos uma clara explanação desses conceitos, quando assevera que

as situações mais radicais de contato linguístico maciço e abrupto dão ensejo à formação, em curto período de tempo, de uma língua nova, distinta em sua estrutura gramatical de todas as outras que concorreram para sua formação (língua pidgin ou língua crioula), não obstante seu léxico seja majoritariamente proveniente de apenas uma das línguas em contato e alguns mecanismos de sua gramática possam ter sido transferidos da gramática das outras línguas [...] Nesta perspectiva, o processo de formação de uma variedade linguística em situação de contato é concebido como variável em seus resultados, em função da gradação nos valores de certas variáveis sociais que o estruturam, de modo que seu resultado não pode ser um pidgin ou um crioulo, mas apenas uma variedade da língua que prevalece na situação de contato. (LUCCHESI, 2015, p. 95)

Assim, faz-se necessário entender o porquê de se afirmar que o processo de constituição histórica do português brasileiro bem como de suas variações constituintes não dão conta de uma língua crioula, mas de um processo de transmissão linguística irregular de tipo mais leve do que a formadora de línguas crioulas. Uma das características desse tipo de transmissão linguística irregular de tipo leve é o uso de formas não marcadas, que, consequentemente, dão na simplificação ou redução de formas gramaticais, ou seja, há uma menor intensidade no nível de erosão dessas formas.

${ }^{6}$ Para Dubois et al. (2014, p.152), "dá-se o nome de crioulos a sabires, pseudossabires, ou pidgins, que, por motivos diversos de ordem histórica ou sociocultural, se tornaram línguas maternas de toda uma comunidade. Não se tem por língua materna um sabir, um pseudossabir ou um pidgin, mas, como milhões de haitianos, pode-se ter um crioulo. [...]. Neles o número de palavras de origem local é muito reduzido, salvo exceções. 
Lucchesi (2015) argumenta que a predominância da transmissão linguística irregular de tipo leve e a não predominância de situações de crioulização típica devem-se principalmente a dois motivos:

o primeiro grande fator a inibir uma crioulização generalizada do português no Brasil teria sido a proporção de falantes da língua dominante. [...] a população branca no Brasil nunca foi superior a $30 \%$, crescendo significativamente no século XIX, quando chegou quase à metade do total. Esse quadro está bastante distante das situações prototípicas de crioulização, como as do Caribe. No Haiti e na Jamaica, a proporção de brancos sempre foi inferior a 10\% durante praticamente todo o período da colonização, e o nível de miscigenação entre brancos e negros foi muito mais baixo do que o observado no Brasil. Portanto, de um modo geral, o acesso aos modelos da língua-alvo no Brasil sempre foi maior do que o que se observa na crioulização. $O$ segundo fator que inibiu a crioulização no Brasil foi a possibilidade de inserção do escravo na sociedade branca, particularmente no caso do escravo nascido no Brasil, o chamado crioulo. (LUCCHESI, 2015, p. 103)

Além disso, Lucchesi e Baxter (2009, p. 112) asseveram que, quando o processo TLI resulta numa língua crioula, há uma tendência de a estrutura gramatical passar por uma organização em que se observam os seguintes fatores:

(i) focalização do constituinte através do seu deslocamento para o início da oração;

(ii) sistema de artigos baseado na distinção entre os níveis de referencialidade 'específico/não-específico', marcados, respectivamente, pela presença/ausência do artigo;

(iii) sistema analítico, em que partículas independentes marcam as categorias verbais de tempo, modo e aspecto;

(iv) orações relativas com cópia pronominal;

(v) estruturas de negação dupla;

(vi) uso de um mesmo verbo para indicar 'posse' e 'existência';

(vii) ausência de cópula em predicados que envolvem adjetivos;

(viii) uso de adjetivos que funcionam como verbos;

(ix) ordem invariável para as orações afirmativas, imperativas e interrogativas;

(x) forma bimorfêmica analítica assumida pelas palavras interrogativas; e

(xi) escassez de construções passivas.

Quando, porém, a referida transmissão de tipo leve acontece, resultando numa variedade da língua lexificadora ${ }^{7}$, observam-se as seguintes características:

(i) eliminação de certos dispositivos gramaticais mais abstratos e de uso restrito da língua alvo;

(ii) recomposição da estrutura gramatical da língua alvo, eliminando a variação ou reduzindo-a a uma pequena escala;

${ }^{7}$ Língua que, em virtude de seu poder e prestígio, é usada como veículo de comunicação verbal imposto a
grupos dominados e que, no caso de línguas pidgins ou crioulas, fornece maior parte de seu léxico formador. 
(iii) manutenção da variação no esquema presença/ausência do dispositivo gramatical da língua alvo;

(iv) alteração nas frequências de uso relativamente à marcação de determinados parâmetros sintáticos;

(v) manutenção da variação no uso do dispositivo gramatical dentro de um esquema de variável ternária - com a variante da língua alvo, uma variante oriunda de um processo original de reestruturação da gramática e a variante zero. (LUCCHESI e BAXTER, 2009, p. 112)

A despeito dessas evidências, dizemos que o português brasileiro é desvelado quando de seu intenso processo de variação, da convivência e de influências de línguas distintas e, nesse mesmo contexto, pela coexistência de relações sociais entre ricos e pobres, dominados e dominadores, a base e o topo da pirâmide, os que tiveram acesso e os que não tiveram acesso a uma escolarização. Tudo isso revela influências diretas do social sobre o linguístico, fazendo com que se descortine na constituição do português brasileiro não apenas o seu caráter heterogêneo e variável, mas também polarizado.

\section{DESVELANDO A POLARIZAÇÃO SOCIOLINGUÍSTICA DO BRASIL}

A realidade sociolinguística brasileira resultante de uma formação sócio-histórica complexa, como foi discutida até aqui, se desvela, nos termos de Lucchesi (2003) e Baxter e Lucchesi (2009), notadamente polarizada.

Serafim da Silva Neto, ainda na segunda metade do século XX, já destacava esta realidade:

os princípios da colonização até 1808 , e daí por diante com intensidade cada vez maior, se notava a dualidade linguística entre a nata social, viveiro de brancos e mestiços que ascenderam, e a plebe, descendente dos índios, negros e mestiços da colônia. (SILVA NETO, 1963, p. 88-89)

Assiste-se, no Brasil do século XX, a uma grande transformação da sociedade, nos moldes do Capitalismo, com os processos de industrialização e urbanização. Isso acarretará no êxodo rural, em que há uma movimentação notável de pessoas do meio rural para os grandes centros, por conta de emprego e tentativa de melhoria de vida, o que, consequentemente, vai ter implicações linguísticas.

Segundo Bortoni-Ricardo (2005),

no século XX, assistimos, porém, a dois fenômenos de notáveis consequências linguísticas: a migração das populações de pequenas cidades e zonas rurais para os grandes centros e a difusão dos meios de comunicação de massa. Instala-se, então, nesses centros, um processo de diglossia, onde atuam duas forças antagônicas: por um lado, o padrão tradicional de redução flexional da própria língua, exacerbado pela situação de contato entre dialetos diferentes; por outro, a pressão do prestígio da norma culta, imposta pela ação da escola, dos meios de comunicação e do status das classes mais favorecidas. (BORTONI-RICARDO, 2005, p. 33) 
Isso reforça a ideia de que no Brasil, de um lado, há a norma culta falada, principalmente, pelos estratos mais altos da sociedade e, do outro, a norma popular falada pelas classes que compõem a base da pirâmide social.

Observa-se, assim, a norma culta tendo como base as orientações tradicionais da gramática normativa, consolidada sobre os modelos lusitanos e que representou, e representa, durante toda a história da constituição linguística brasileira, o uso linguístico da minoria privilegiada economicamente, com acesso a uma escolarização consolidada e com marcas de dominação na conjuntura social. Inclusive é nesse estrato social que tem se sustentado o mito da unidade da língua, que, segundo Bagno (2015), urge ser desmitificado e desmascarado.

Já na norma popular verificam-se usos desviantes do padrão determinado pela tradição gramatical. E a sociedade caracteriza muitas vezes de forma estigmatizada os membros das classes sociais mais baixas às quais foram impingidas as marcas de pouco ou nenhum acesso à escolarização e em cuja estrutura linguística percebem-se fortemente os reflexos da aquisição do português de maneira defectiva, tendo em vista o contato massivo entre o português e, principalmente, as línguas africanas, conforme já foi esclarecido anteriormente com base nos estudos de Baxter e Lucchesi (2009).

É salutar ressaltar que esse processo tão atual é a representação do que foi pintado historicamente no quadro das relações sociolinguísticas no Brasil. Mussa (1991) assevera que, a partir do século XVIII,

o fato linguístico mais importante é com certeza o contato entre os dialetos de Portugal e os dialetos do Brasil. Do ponto de vista sociolinguístico, o português dos estratos superiores pendia para os falares europeus, uma vez que a grande parcela dos que encimavam a sociedade colonial era portuguesa. Já nos estratos inferiores, é provável que falares mais caracteristicamente brasileiros já tivessem despontado, diferindo do português europeu, embora não infensos à sua influência. (MUSSA, 1991, p. 159)

Quando se propõe trazer à baila os conceitos de norma sociolinguística, busca-se, dentro desta revisitação histórica da constituição do português brasileiro, salientar como há uma convergência de fatores sociais na estrutura linguística do PB.

Assim, desse panorama, herdamos diversas características morfossintáticas que distinguem o PB do português europeu a exemplo da perda da concordância no sintagma verbal e no sintagma nominal (Os menino fez uma gritaria sem fim), do uso de relativa cortadora (... mas foi a confusão que os menino falou) e com pronome lembrete $(O$ menino que eu gosto dele estava lá na hora), a alternância do presente do subjuntivo pelo presente do indicativo (Você quer que eu traz, as cadeira para você??), entre outras, que compõem o que chamamos de realidade sociolinguística do português brasileiro.

\section{CONSIDERAÇÕES FINAIS}

O mito de um português único, imutável e homogêneo, paulatinamente, tem sido desconsiderado no cenário brasileiro. A mais nobre tarefa dos estudos sociolinguísticos 
no âmbito no âmbito do Brasil é legar uma discussão responsável sobre o que de fato é o PB bem como descrever e analisar as complexas formas de ele ter se constituído como é, rico e variável.

Foi pensando nos aspectos para um estudo sociolinguístico, que este estudo se desenvolveu. Foi observado ao longo das seções aqui apresentadas o processo de constituição sócio-histórica do português brasileiro, por meio de reflexões sobre o contato entre línguas e seu lugar na formação das variedades do português em nosso País.

Desse conceito maior, empreendeu-se uma análise do papel dos negros escravizados tanto na estrutura social, na qual assumem o lugar formador da base, como, e consequentemente, na estrutura linguística do PB. Junto aos elementos negro e europeu, apresentamos, no tripé do $\mathrm{PB}$, os índios que também vão interferir e influenciar na estrutura e formação de nossa língua.

Discutiu-se também o processo de transmissão linguística irregular, colocando em questão o fato de, no Brasil, a TLI, que se apresenta de forma leve, não ter convergido para um crioulo típico, mas para uma variedade do português falado no território.

Por fim, apresentou-se também a histórica e tão atual polarização sociolinguística, em cujo âmago convivem normas representativas de um percurso sócio-histórico que se reafirma hodiernamente como foi outrora, no sentido de repartição da sociedade a partir da norma da elite e da norma popular.

Por fim, esperamos com este estudo contribuir para que, à medida que se compreenda a complexidade da formação sócio-histórica do PB, possa-se também assistir a novas formas de conceber as variedades do português brasileiro dentro de suas riquezas linguísticas e históricas.

\section{REFERÊNCIAS}

BAGNO, Marcos. Preconceito linguístico: o que é, como se faz. São Paulo: Parábola, 2015.

BORTONI-RICARDO, Stella Maris. Nós cheguemu na escola, e agora? São Paulo: Parábola, 2005.

DUBOIS, J. et al. Dicionário de linguística. 2. ed. São Paulo: Cultrix, 2014.

FERNANDES, Cláudio. Língua geral no contexto do Brasil Colonial. Brasil Escola. Disponível em: $<$ http://brasilescola.uol.com.br/historiab/lingua-geral-no-contexto-brasil-colonial.htm $>$. Acesso em: 27 ago. 2017.

LUCCHESI, Dante. Lingua e sociedade partidas: a polarização sociolinguística do Brasil. São Paulo: Contexto, 2015.

LUCCHESI, Dante; BAXTER, Alan. A transmissão linguística irregular. In: LUCCHESI, Dante; BAXTER, Alan; RIBEIRO, Ilza (Org.). O português afro-brasileiro. Salvador: EDUFBA, 2009. p. 101-124.

LUCCHESI, Dante; BAXTER, Alan; RIBEIRO, Ilza (Org.). O português afro-brasileiro. Salvador: EDUFBA, 2009.

MATTOS E SILVA, Rosa Virgínia. Ensaios para uma sócio-bistória do português brasileiro. São Paulo: Parábola, 2004. 
MUSSA, Alberto B. N. O papel das línguas africanas na história do português do Brasil. Rio de Janeiro: UFRJ, 1991 (Dissertação de Mestrado em Língua Portuguesa).

NARO, Anthony Julius. O dinamismo das línguas. In: MOLLICA, Maria Cecília; BRAGA, Luiza Braga (Org.). Introdução à sociolinguística: o tratamento da variação. 4. ed., 3. reimpressão. São Paulo: Contexto, 2015. p. 43-50.

RODRIGUES, Aryon Dall'Igna. Línguas indígenas: 5000 anos de descobertas e perdas. D.E.L.T.A., v. 9, n. 1, 1993, São Paulo. p. 83-103.

SILVA NETO, Serafim. Introdução ao estudo da língua portuguesa no Brasil. $2^{\mathrm{a}}$ ed. Rio de Janeiro: INL, 1963.

TEIXEIRA, Eliana S. Pitombo. Aspectos da pronominalização do português vernacular de Luanda: uma comparação com o português do Brasil. In: LOPES, Norma da Silva; BULHÕES, Lígia Pelon da Silva; CARVALHO, Cristina dos Santos (Org.). Sociolinguística: estudo da variação, da mudança e da sócio-história do português brasileiro. Feira de Santana: EDUEFS, 2013. p. 145167. 